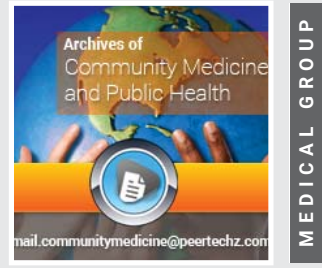

\title{
Challenges and opportunities of medical research in Libya
}

\author{
Aisha Nasef ${ }^{1,2 *}$ \\ ${ }^{1}$ Authority of Natural Science Research and Technology, Libya \\ ${ }^{2}$ Scientific Council of Laboratory Medicine, Medical Specialty Council, Libya
}

Received: 05 February, 2020

Accepted: 10 March, 2020

Published: 11 March, 2020

*Corresponding author: Aisha Nasef, Authority of Natural Science Research and Technology, Libya, Tel: +218910419561;

E-mail: Nasef@doctor.com

https://www.peertechz.com

\section{Check for updates}

Medical research is needed at community, hospital and individuals levels. Governments and hospitals benefit from medical research to solve problems, identify priorities, monitoring intervention, analyzing out come and benchmarking. Medical research help in assessment of community health status.

Research culture is not formed in Libya yet and resulted in low publication rate $[1,2]$. This can be attributed to the following main factors Figure 1.

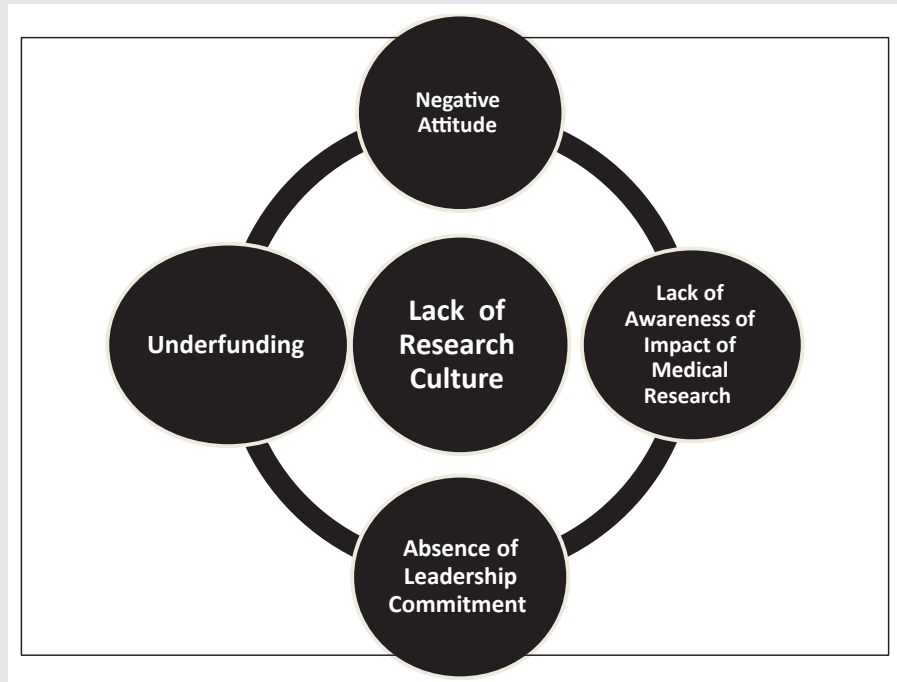

Figure 1: Underlying Causes of Lack of Research Culture in Libya.

In Libya, challenges are many, and can be divided into challenges facing research in developing countries, as well as country specific challenges. The following table list all specific challenges for medical research in Libya at strategic, tactic and operational level.

\section{Specific challenges in Libya}

\section{Challenges at strategic level}

1. Lack of country well-defined strategy, vision, objectives, structure, style and values.

2. Under estimation of research value and importance by stake holders.

3. Lack of allocation of suitable percentage from Gross Domestic Product (GDP) to fund research.

\section{Challenges at tactic level}

4. Ministry of health are not involved in scientific research even at strategic level.

5. Lack of know how in research conduction, resources allocation and skills.

6. Graduation project is not included in colleges and in high school, and it is not mandatory in all Libyan faculties and not well constructed or supervised.

7. Local funding system has a lot of shortcomings, and it's is not justified, with no equity or personal accountability.

8. No structured research activity in universities.

9. Deans as well as teaching staffs of many medical faculties are Board certified and accepted as Ph.D. equivalence.

10. Professional, even who was assigned on the top of medical faculties, did not value the scientific background or need and importance of research in establishment of evidence based medical practice despite being western countries graduates. 
11. Libyans focus in simple descriptive studies and do not address new therapies and interventional studies, or reporting diseases encountered in Libya. This is attributed to absence of required resources; skills and competency, tools, technology, equipment's and Knowledge.

12. The most unacceptable drawbacks in Libya, is absence of state of art documentation and records in all health facilities. This represent an extra obstacles for Libyan researchers.

\section{Challenges at operational level}

In Libya, there are two centers designated for medical and biomedical research, National Medical Research Center (NMRC), and Biomedical Research Center (BRC). Both are located in Western part of Libya and have their own financial budget and administration. They are under the umbrella of National Authority of Natural Science Research and Technology that is under the Umbrella of Ministry of Education.

13. Both centers work independently of planning ministry (Strategic) or health Ministry (Tactic) or medical centers and institutes (Operational).

14. Both centers never had a research on health management, policies and planning.

15. Both centers have no ongoing national Libyan projects in urgent or prevalent health problems as it should be with allocation of resources (human, money, and infrastructure, collaboration, phases, recommendation, and adoption of it) .

16. Both do not cope with the demanding current problems, such as mal-nutrition, mental and psycahtric cases especially Post Traumatic Stress Syndrome (PTDS), addiction during this long period of civil war, displacement, explosions, killing, bombing, etc.
17. Research centers were located far away from Capital, where main scientific bodies, Universities, primary and tertiary level hospitals as well as medical and biomedical researchers are present.

18. Lack of equipped research laboratories, and when it's equipped it is, either stolen or destroyed as a result of current war, or they are not maintained and most of equipment's are out of orders, or with no continuous supplies of spare parts, consumables or reagents!!.

19. Research centers suffer from non-qualified clerk and non-efficient supportive employees who are fully paid with promotions, and rewards!!. This represent additional burden on non-wisely allocated budget and it should be out-sourced.

20. Competent or contributing researcher in these centers are not the majority. In 2013 they represented less 10 percent in NMRC, while the employees are more than 200. Dispense are allocated for non-research issues such as; employees promotions, vehicles, mobiles, computers, travel, accommodation, building maintenance and catering, etc.

21. Naming of directors is connection based rather than competency based, despite single trail on 2012 for CV based hiring. Grants allocated to non-competent, noexperienced individuals.

22. Directors are not accountable, they can stay for long duration with no justified or significant production in biomedical fields. They have control of work environment.

23. No accountability of these centers productivity. Center have the control of decision of who work, where and how. Millions allocated for non-structured research, with no evidence based guidelines or recommendation on hot topics. They work in isolation of medical faculties.
1. Assignments of medical research consultant/ adviser in National authority of natural science research and technology. This could help in setting clear objectives at strategic, tactic and operational levels and help in coordination of all centers and stakeholders.

2. Interest notices among medical students in research. Medical students established medical student research council. They had a number of very good journal clubs and scientific days. One was designated for importance of medical research in medical education, new modalities, osce exam objectivity. Libya could contain and invest in those motivated and interested potential future researchers!.

3. Publication based promotion of teaching staffs in Libyan universities. Pressure to publish enough papers for promotion represent $\mathrm{n}$ double edge sword. and should be taken in consideration. It could motivate publication, or it could force to wrong doing research culture. So, this need to be studies and clarified and used in motivation with a well-established strategy and defined objective.

4. Increased awareness and establishments of Libyan, Arabic and international groups on social media such as Libyan medical research network, Libyan group for medical research and publication, scientific research center, researcher.

1. Adoption the proposal of health research incubators establishments in Libya, for coordination of effective and efficient research groups work

2. Recommendation, for all countries to commit at least $0.2 \%$ of its GDP to health research, and approval of requested rise of medical research funding in constitution as to be comparable to developed countries [3].

3. Libya could contribute to world science by focusing on Libya-specific disease. Working with UNESCO, ALECSO, African Union Science, Technology and Innovation Strategy for Africa 2024 could help a lot [4].

4. Approval and establishments of National Institute of Health (NIH) proposal by ministry of health in Tripoli, as well as establishment of Libya Research Council (LRC) in with board from burlement, ministers, universities and faculties order to set goals and objectives of medical research in Libya.

Citation: Nasef A (2020) Challenges and opportunities of medical research in Libya. Arch Community Med Public Health 6(1): 028-030. 
24. Lack of supportive teams such as statistic department, scientific writing expert, etc.

25. The most difficult research in Libya, those needs advanced technology and know-how such as in clinical pathology and clinical trials, etc.

\section{Conclusion}

Promotion and increase awareness of importance of academic research in making evidence based decision and in self-performance by professional and decision makers could help a lot in solving current Libyan health problems.

This article represent a first step to improve current status of medical research in Libya. Taking all these challenges and opportunities in account, and starting by workshops with all stakeholders for further identification of all other positive and negative factors, could promote medical research in Libya.

\section{References}

1. Ahmed MO, Daw MA, van Velkinburgh JC (2017) An evolving research culture: Analysis of biomedical publications from Libya, 2003-13. Res Eval 4: 284-291. Link: http://bit.ly/2x1L8vn

2. Benamer HT, Bredan A, Bakoush O (2009) A negative trend of biomedical research in Libya: A bibliometric study. Health Info Libr J 26: 240-245. Link: http://bit.ly/33oHN5r

3. Reida M El Oakley (2013) Underfunding Health Research: Failure of Diplomacy or Lack of Political-Will? Int J Health Res Innovation 1: 19-27. Link: http://bit.ly/2Wql809

4. Link: http://bit.ly/2IUbqlG

\section{Discover a bigger Impact and Visibility of your article publication with}

\section{Peertechz Publications}

\section{Highlights}

* Signatory publisher of ORCID

- Signatory Publisher of DORA (San Francisco Declaration on Research Assessment)

* Articles archived in worlds' renowned service providers such as Portico, CNKI, AGRIS, TDNet, Base (Bielefeld University Library), CrossRef, Scilit, J-Gate etc.

* Journals indexed in ICMJE, SHERPA/ROMEO, Google Scholar etc.

* OAI-PMH (Open Archives Initiative Protocol for Metadata Harvesting)

* Dedicated Editorial Board for every journal

* Accurate and rapid peer-review process

* Increased citations of published articles through promotions

* Reduced timeline for article publication

Submit your articles and experience a new surge in publication services (https://www.peertechz.com/submission).

Peertechz journals wishes everlasting success in your every endeavours.

Copyright: ( $) 2020$ Nasef A. This is an open-access article distributed under the terms of the Creative Commons Attribution License, which permits unrestricted use, distribution, and reproduction in any medium, provided the original author and source are credited. 